\title{
INOVASI BARU PENGGUNAAN MULTIMEDIA INTERAKTIF DAN MOBILE LEARNING DALAM MENINGKATKAN PRESTASI MAHASISWA PENDIDIKAN TEKNIK ELEKTRO UNIVERSITAS SULTAN AGENG TIRTAYASA PADA MATA KULIAH LOGIKA FUZZY
}

\author{
I r w a n t o \\ Pendidikan Teknik Elektro Fakultas Keguruan dan Ilmu Pendidikan Universitas Sultan Ageng \\ Tirtayasa, Serang-Banten \\ Email: irwanto.ir@untirta.ac.id
}

\begin{abstract}
Abstrak
Penelitian ini dilakukan atas dasar permasalahan prestasi belajar mahasiswa pada mata kuliah logika fuzzy di program studi pendidikan teknik elektro Universitas Sultan Ageng Tirtayasa belum mencapai kriteria ketuntasan minimum, sehingga tujuan dalam pembelajaran belum tercapai dengan baik. Salah satu upaya untuk memperbaiki nilai prestasi belajar mahasiswa adalah menggunakan inovasi baru yaitu aplikasi media dalam pembelajaran yang dalam hal ini penggunaan multimedia interaktif dan mobile learning. Adapun tujuan yang ingin di capai dalam penelitian ini adalah untuk mengetahui (1) peningkatan prestasi belajar mahasiswa yang menggunakan multimedia interaktif pada mata kuliah logika fuzzy di program studi pendidikan teknik elektro (2) peningkatan nilai prestasi belajar mahasiswa yang menggunakan mobile learning pada mata kuliah logika fuzzy di program studi pendidikan teknik elektro (3) perbedaan dalam peningkatan prestasi belajar mahasiswa antara yang menggunakan multimedia interaktif dan mobile learning pada mata kuliah logika fuzzy di program studi pendidikan teknik elektro di universitas sultan ageng tirtayasa. Metode penelitian yang digunakan dalam penelitian ini adalah metode eksperimen dengan pendekatan kuantitatif. Bentuk eksperimen yang digunakan adalah preexperimental design, dengan one-group pretest-posttest design. Hasil penelitian adalah (1) dalam penggunaan multimedia interaktif dapat meningkatkan nilai prestasi belajar mahasiswa pada mata kuliah logika fuzzy di program studi pendidikan teknik elektro universitas sultan ageng tirtayasa (2) penggunaan mobile learning dapat meningkatkan nilai prestasi belajar mahasiswa pada mata kuliah logika fuzzy di program studi pendidikan teknik elektro universitas sultan ageng tirtayasa (3) peningkatan nilai prestasi belajar mahasiswa pendidikan teknik elektro universitas sultan ageng tirtayasa yang menggunakan multimedia interaktif lebih tinggi dari pada mahasiswa yang menggunakan mobile learning pada mata kuliah logika fuzzy tersebut.
\end{abstract}

Kata Kunci: logika fuzzy, multimedia interaktif, mobile learning, prestasi belajar.

\begin{abstract}
This research was conducted on the basis of the problem of student learning achievement in fuzzy logic courses in the electrical engineering education program at Sultan Ageng Tirtayasa University has not yet reached the minimum completeness criteria, so that the objectives in learning have not been achieved properly. One effort to improve the value of student learning achievement is to use new innovations, namely media applications in learning, in this case the use of interactive multimedia and mobile learning. The objectives to be achieved in this research are to find out (1) improvement in student learning achievement using interactive multimedia in fuzzy logic courses in electrical engineering education courses (2) increase in the value of student learning achievement using mobile learning in logic courses fuzzy in the electrical engineering education study program (3) differences in improving student achievement between those who use interactive multimedia and mobile learning in fuzzy logic courses in the electrical engineering education study program at the university of sultan ageng tirtayasa. The research method used in this study is an experimental method with a quantitative approach. The form of experiment used was pre-experimental design,
\end{abstract}


with one-group pretest-posttest design. The results of the study are (1) the use of interactive multimedia can increase the value of student learning achievement in fuzzy logic courses in the electrical engineering education program of the sultan ageng tirtayasa university (2) the use of mobile learning can increase the value of student learning achievement in fuzzy logic courses in the program Electrical Engineering Education University of Sultan Ageng Tirtayasa (3) Increasing the value of student achievement in Electrical Engineering University of Sultan Ageng Tirtayasa who uses interactive multimedia is higher than students who use mobile learning in the fuzzy logic course.

Keywords: fuzzy logic, interactive multimedia, mobile learning, learning achievement.

\section{PENDAHULUAN}

Pendidikan Nasional adalah pendidikan yang berdasarkan Pancasila dan Undang-Undang Dasar 1945 yang berakar pada nilai-nilai agama, kebudayaan nasional Indonesia dan tanggap terhadap tuntutan perubahan zaman. Dalam Undang Undang Nomor 20, Tahun 2003, tentang Sistem Pendidikan Nasional Pasal 3 disebutkan, bahwa:

Pendidikan Nasional berfungsi mengembangkan kemampuan dan membentuk watak serta peradaban bangsa yang bermartabat dalam rangka mencerdaskan kehidupan bangsa, bertujuan untuk berkembangnya potensi peserta didik agar menjadi manusia yang beriman dan bertakwa kepada Tuhan Yang Maha Esa, berakhlak mulia, sehat, berilmu, cakap, kreatif, mandiri, dan menjadi warga negara yang demokratis serta bertanggung jawab.

Berdasarkan hal tersebut di atas terkandaung makna filosofi pendidikan yang lebih mengutamakan proses pendidikan yang tidak terjebak pada banyaknya materi yang harus disampaikan kepada peserta didik dan harus dikuasai, melainkan bagaimana terbentuknya generasi bangsa yang mampu menyikapi masa depan dengan handal, cerdas, mempunyai komitmen moral yang tinggi serta semangat pengabdian yang kuat sehingga tujuan nasional terwujud melalui optimalisasi dalam tercapainya tujuan pendidikan nasional.

Teknologi pendidikan lebih diutamakan dalam pembentukan dan penguasaan kompetensi atau kemampuan-kemampuan praktis, bukan pengawetan dan pemeliharaan budaya lama. Dalam konsep pendidikan teknologi, isi pendidikan dipilih oleh tim ahli bidang-bidang khusus. Isi pendidikan berupa data-data obyektif dan keterampilan-keterampilan yang yang mengarah kepada kemampuan vokasional isi disusun dalam bentuk desain program atau desain pengajaran dan disampaikan dengan menggunakan bantuan media elektronika dan para peserta didik belajar secara individual. Peserta didik berusaha untuk menguasai sejumlah besar bahan dan pola-pola kegiatan secara efisien tanpa refleksi. Keterampilanketerampilan barunya segera digunakan dalam masyarakat. Pendidik berfungsi sebagai direktur belajar (director of learning), lebih banyak tugas-tugas pengelolaan dari pada penyampaian dan pendalaman bahan. Teknologi pendidikan menjadi sumber untuk pengembangan model kurikulum teknologis, yaitu model kurikulum yang bertujuan memberikan penguasaan kompetensi bagi para peserta didik, melalui metode pembelajaran individual, media buku atau pun elektronik, sehingga mereka dapat menguasai keterampilan-keterampilan dasar tertentu.

Di antara produk teknologi dalam pendidikan khususnya dalam pembelajaran merupakan penggunaan inovasi baru misalnya pembelajaran yang memanfaatkan HP sebagai basis atau sarana belajar oleh mahasiswa. Mobile learning (m-learning) mengacu kepada penggunaan perangkat IT genggam dan bergerak seperti PDA, telepon genggam, laptop dan tablet PC dalam pembelajaran 
dan pengajaran. Terkait dengan itu jumlah pengguna perangkat bergerak yang banyak, mobile learning dapat dijadikan salah satu alternatif untuk memecahkan permasalahan dalam bidang pendidikan di sekolah khususnya di perguruan tinggi. Namun kenyataan di lapangan, masih banyak guru atau dosen yang belum memanfaatkan teknologi informasi dan komunikasi dalam proses pembelajaran. Walaupun menggunakan TIK, guru dan dosen hanya menanyakan materi yang ada dalam buku tanpa menggunakan multimedia interaktif. Guru dan dosen cenderung lebih senang menggunakan metode ceramah dan menjejali otak mahasiswa dengan materimateri dengan catatan. Hal ini dapat dilihat dari mahasiswa jurusan pendidikan vokasional teknik elektro tahun 2016-2017 prestasi belajarnya di bawah nilai yang ditentukan atau nilai standar yaitu 50 sehingga dibutuhkan suatu perubahan inovasi baru dalam pembelajaran untuk mata kuliah logika fuzzy di jurusan pendidikan vokasional teknik elektro fakultas keguruan dan ilmu pendidikan di universitas sultan ageng tirtayasa.

Berdasarkan latar belakang masalah tersebut di atas peneliti perlu melakukan suatu upaya untuk memperbaiki rendahnya hasil belajar mahasiswa pada jenjang perguruan tinggi (PT) terutama di jurusan pendidikan vokasional teknik elektro universitas sultan ageng tirtayasa tersebut. Dalam penelitian ini diharapkan dapat menemukan inovasi baru dalam pembelajaran khususnya mata kuliah logika fuzzy di fakultas FKIP, program studi pendidikan vokasional teknik elektro universitas sultan ageng tirtayasa. Adapun tujuan penelitian ini adalah untuk mengetahui: (1) peningkatan prestasi belajar mahasiswa yang menggunakan multimedia interaktif pada mata kuliah logika fuzzy di jurusan pendidikan teknik elektro FKIP Untirta (2) peningkatan prestasi belajarmahasiswa yang menggunakan mobile learning pada mata kuliah logika fuzzy di jurusan pendidikan teknik elektro FKIP Untirta (3) perbedaan peningkatan prestasi belajar mahasiswa antara yang menggunakan multimedia interaktif dan mobile learning pada mata kuliah logika fuzzy di jurusan pendidikan vokasional teknik elektro FKIP Universitas sultan ageng tirtayasa.

Istilah media berasal dari bahasa latin yang merupakan bentuk jamak dari medium. Secara harfiah berarti perantara atau pengantar. Pengertian umumnya adalah segala sesuatu yang dapat menyalurkan informasi dari sumber informasi kepada penerima informasi. Media menurut AECT adalah segala sesuatu yang digunakan orang untuk menyalurkan pesan, sedangkan Gagne mengartikan media sebagai jenis komponen dalam lingkungan peserta didik yang dapat merangsang mereka untuk belajar. Briggs mengartikan media sebagai alat untuk memberikan perangsang bagi peserta didik agar terjadi proses belajar.

Istilah pembelajaran lebih menggambarkan usaha tenaga pendidik untuk membuat belajar para peserta didiknya. Kegiatan pembelajaran tidak akan berarti jika tidak menghasilkan kegiatan belajar pada para peserta didiknya. Kegiatan belajar hanya akan berhasil jika si belajar secara aktif mengalami sendiri proses belajar. Seorang tenaga pendidik tidak dapat mewakili belajar peserta didiknya. Seorang peserta didik belum dapat dikatakan telah belajar hanya karena ia sedang berada dalam satu ruangan dengan tenaga pendidik yang sedang mengajar. Pekerjaan mengajar tidak selalu harus diartikan sebagai kegiatan menyajikan materi pelajaran. Meskipun penyajian materi pelajaran memang merupakan bagian dari kegiatan pembelajaran, tetapi bukanlah satusatunya. Masih banyak cara lain yang dapat dilakukan tenaga pendidik untuk 
membuat peserta didik belajar. Peran yang seharusnya dilakukan tenaga pendidik adalah mengusahakan agar setiap peserta didik dapat berinteraksi secara aktif dengan berbagai sumber balajar yang ada.

Media pembelajaran adalah media yang digunakan dalam pembelajaran, yaitu meliputi alat bantu tenaga pendidik dalam mengajaserta sarana pembawa pesan dari sumber belajar ke penerima pesan belajar (peserta didik). Sebagai penyaji dan penyalur pesan, media belajar dalam hal-hal tertentu bisa mewakili tenaga pendidik menyajiakan informasi belajar kepada peserta didik. Jika program media itu didesain dan dikembangkan secara baik, maka fungsi itu akan dapat diperankan oleh media meskipun tanpa keberadaan tenaga pendidik.

Peranan media yang semakin meningkat sering menimbulkan kekhawatiran pada tenaga pendidik. Namun sebenarnya hal itu tidak perlu terjadi, masih banyak tugas tenaga pendidik yang lain seperti: memberikan perhatian dan bimbingan secara individual kepada peserta didik yang selama ini kurang mendapat perhatian. Kondisi ini akan teus terjadi selama tenaga pendidik menganggap dirinya merupakan sumber belajar satu-satunya bagi peserta didik. Jika tenaga pendidik memanfaatkan berbagai media pembelajaran secara baik, tenaga pendidik dapat berbagi peran dengan media. Peran tenaga pendidik akan lebih mengarah sebagai manajer pembelajaran dan bertanggung jawab menciptakan kondisi sedemikian rupa agar peserta didik dapat belajar. Untuk itu tenaga pendidik lebih berfugsi sebagai penasehat, pembimbing, motivator dan fasilitator dalam kegiatan belajar mengajar. Secara umum manfaat media pembelajaran adalah memperlancar interaksi antara tenaga pendidik dengan peserta didik sehingga kegiatan pembelajaran lebih efektif dan efisien.

Multimedia sebagai sarana dalam pembelajaran secara etimologis berasal dari kata multi (bahasa latin, nouns yang berarti banyak, bermacam-macam) dan medium (bahasa latin yang berarti sesuatu yang dipakai untuk menyampaikan atau membawa sesuatu). Kata medium dalam arti lain yaitu sebagai alat untuk mendistribusikan dan mempresentasikan informasi. Jadi subjek multimedia adalah informasi yang dapat dipresentasikan kepada manusia.

Dosen adalah seorang presenter yaitu yang mampu memberikan informasi pengetahuan yang penting, benar, dan baik juga bermanfaat bagi kehidupan masa depan peserta didik di masa yang akan datang. Dosen bukan seorang yang apatis, pesimistis, apalagi anti terhadap nilai-nilai kebenaran, kebaikan dan nilai luhur kemanusiaan. Jabatan guru merupakan jabatan profesional, namun demikian guru merupakan seorang manusia biasa yang mempunyai kelebihan dan kelemahan, terutama dalam menyikapi dan memahami perkembangan berbagai ilmu pengetahuan yang begitu luas dan kompleks.

Menurut Sajaya (2009) mengatakan bahwa fungsi dan manfaat media pembelajaran adalah sebagai berikut: (a) Menangkap suatu objek atau peristiwa-peristiwa tertentu yang penting atau objek yang langka dapat diabadikan dengan foto, film, atau direkam melalui video atau audio, kemudian peristiwa itu disimpan dan dapat digunakan lagi manakala diperlukan; (b) Memanipulasi keadaan, peristiwa atau objek tertentu, maksudnya melalui media pembelajaran seorang guru dapat menyajikan bahan pelajaran yang bersifat abstrak menjadi konkrit sehingga mudah dipahami dan dapat menghilangkan verbalisme; (c) Menambah gairah motivasi belajar siswa. Diharapkan dengan menggunakan media pembelajaran, motivasi belajar siswa 
dapat bertambah sehingga kegiatan belajar menjadi lebih menyenangkan hal ini dibuktikan dengan perhatian peserta didik terhadap kegiatan penyampaian materi pelajaran; (d) Media pembelajaran memiliki nilai praktis, artinya bisa digunakan sesuai kebutuhan serta situasi dan kondis bagaimana pun.

Bentuk penggunaan komputer sebagai media pembelajaran berupa multimedia interaktif yang mana merupakan sarana pembelajaran yang berisi materi, metode, batasan-batasan, dan cara mengevaluasi yang dirancang secara sitematis dan menarik untuk mencapai sebuah kompetensi yang diharapkan sesuai dengan kompleksitasnya. Selanjutnya Susiana \& Riyana (2009:126) mengemukakan bahwa:

"Multimedia interaktif sebagai bahan ajar bertujuan: (1) memperjelas dan mempermudah penyajian pesan agar tidak terlalu bersifat verbalistist, (2) mengatasi keterbatasan ruang, waktu, dan daya indera para siswa, (3) dapat digunakan secara tepat dan bervariasi, seperti meningkatkan motivasi dan gairah belajar siswa untuk menguasai materi pelajaran secara utuh, mengembangkan kemampuan siswa dalam berinteraksi langsung dengan lingkungan dan sumber belajar lainnya terutama bahan ajar yang berbasis ICT memungkingkan para siswa untuk belajar secara mandiri sesuai dengan kemampuan dan minatnya."

Kegiatan pembelajaran merupakan upaya konstruktif yang dibangun oleh para pengajar untuk menanamkan konsep-konsep penting yang harus tertanam dan tumbuh dalam pribadi peserta didik, artinya pembelajaran tidak menjadi sekedar upaya mentransformasi ilmu pengetahuan melainkan memberikan kesadaran pada diri peserta didik tentang pentingnya pelaksanaan pembelajaran sebagai bekal para peserta didik di masa yang akan datang.
Menurut Darmawan (2015:150) menyatakan bahwa alasan, kenapa mobile learning saat ini dikembangan: (1) mobile learning dapat digunakan kapanpun dan dimanapun (dalam jaringan atau diluar jaringan) (2) mobile learning cakupannya luas, dapat menggunakan jaringan GSM atau jaringan seluler (GSM, CDMA, GPRS) tanpa harus membangun sendiri, karena karena jaringan elah tersedia dimanamana (3) mobile learning Integrasi dengan sistem yang ada khususnya mampu berintegrasi dengan e-learning, berintegrasi dengan sistem penyelenggaraan pendidikan (sistem informasi akademik), serta dapat berintegrasi dengan sistem instant messeging. Jadi Mobile learning adalah suatu pendekatan pembelajaran yang melibatkan device (perangkat) bergerak sepert telepon genggam, PDA, Laptop dan tablet PC, dimanapun pembelajaran dapat mengakses materi, arahan dan aplikasi yang berkaitan dengan pelajaran tanpa dibatasi oleh ruangan dan waktu, dimanapun dan kapanpun mereka berada.

\section{METODE PENELITIAN}

Pendekatan dalam penelitian ini adalah pendekatan kuantitatif karena dalam penelitian ini disajikan dengan angka-angka. Metode yang digunakan dalam penelitian ini adalah metode penelitian eksperimen, bentuk eksperimen yang digunakan adalah preexperimental design. Bentuk preexperimental design yang dipilih onegroup pretest-posttest design yaitu suatu kelompokyang diberi pretest sebelum perlakuan dan dilakukan posttest setelah perlakuan. Teknik pengumpulan data yang digunakan dalam penelitian yaitu tes dan observasi. Lokasi penelitian di fakultas keguruan dan ilmu pendidikan jurusan pendidikan vokasional teknik elektro universitas sultan ageng tirtayasa serang banten. Sampel penelitian ini adalah mahasiswa semester enam dengan 
jumlah 20 mahasiswa yang mengambil mata kuliah pilihan logika fuzzy (PTE614314). Dalam hal ini 20 mahasiswa saya bagi menjadi dua kelompok yaitu 10 mahasiswa menggunakan multimedia interaktif dan 10 mahasiswa lain menggunakan mobile learning.

\section{HASIL PENELITIAN DAN PEMBAHASAN}

Universitas sultan ageng tirtayasa merupakan salah satu perguruan tinggi negeri di Banten memiliki fakultas keguruan dan ilmu pendidikan serta mempunyai jurusan pendidikan vokasional teknik elektro (PVTE). Program studi PVTE pada semester enam memiliki mata kuliah wajib sebanyak 18 SKS serta mempunyai mata kuliah pilihan diantaranya adalah logika fuzzy, sistem komunikasi optik, pemrograman lanjut, transformator dan proteksi sistem tenaga dengan total SKS sebanyak 10 SKS.

\section{Peningkatan prestasi belajar mahasiswa yang menggunakan multimedia interaktif pada mata kuliah logika fuzzy di PVTE UNTIRTA.}

Hasil penelitian ini ditemukan bahwa nilai rata-rata dalam peningkatan prestasi belajar mahasiswa yang menggunakan multimedia interaktif tidak kurang dari 0.5. dengan kata lain hipotesis ke satu yang diajukan oleh peneliti yaitu terdapat peningkatan prestasi belajar mahasiswa yang menggunakan multimedia interaktif pada mata kuliah logika fuzzy di jurusan PVTE Untirta diterima. Merujuk pada interpretasi gain dengan nilai rata-rata sebesar 0.80 atau $80 \%$ maka peningkatan prestasi belajar pada kelas yang menggunakan multimedia interaktif termasuk dalam kategori tinggi.

\section{Peningkatan prestasi belajar mahasiswa yang menggunakan mobile learning pada mata kuliah logika fuzzy di PVTE UNTIRTA.}

Hasil pengujian hipotesis dengan menggunakan SPSS versi 16 didapatkan hasil nilai rata-rata dalam peningkatan prestasi belajar mahasiswa yang menggunakan mobile learning tidak kurang dari 0.5. dengan kata lain, hipotesis ke dua yang peneliti ajukan yaitu terdapat peningkatan hasil belajar mahasiswa yang menggunakan mobile learning pada mata kuliah logika fuzzy di jurusan PVTE Untirta di terima. Dengan merujuk pada interpretasi gain, dengan nilai rata-rata sebesar 0.570 atau $57 \%$ maka dalam peningkatan prestasi belajar pada kelas yang menggunakan mobile learning termasuk dalam kategori sedang.

3. Peningkatan prestasi belajar mahasiswa yang menggunakan mobile learning pada mata kuliah logika fuzzy di PVTE UNTIRTA.

Berdasarkan hasil penelitian menyatakan bahwa rerata gain hasil prestasi belajar kelas eksperimen multimedia interaktif sebesar 0.800 dan gain hasil belajar kelas mobile learning adalah 0.570. untuk menjawab hipotesis maka hasil pengolahan uji independent samples t-test sebesar $0.000<$ nilai $\alpha$ (0.05) maka Ho ditolak atau Ha diterima. Maka dapat ditarik kesimpulan bahwa ada perbedaan peningkatan prestasi belajar yang signifikan antara kelompok eksperimen multimedia interaktif dan kelompok eksperimen mobile learning. Dari hasil penelitian pula didapatkan hasil t-hitung sebesat 7.6026 dan t-tabel sebesar 1.9991, maka dapat di tarik kesimpulan bahwa terdapat perbedaan nilai rata-rata peningkatan hasil prestasi belajar antara mahasiswa yang menggunakan multimedia interaktif dan mobile learning pada mata kuliah logika fuzzy di fakultas keguruan dan ilmu pendidikan universitas sultan ageng tirtayasa.

Hipotesis ketiga yang peneliti ajukan yaitu terdapat perbedaan peningkatan prestasi belajar mahasiswa antara yang menggunakan multimedia interaktif dan mobile learning pada mata 
kuliah logika fuzzy di jurusan PVTE fakultas keguruan dan ilmu pendidikan universitas sultan ageng tirtayasa di terima. Dapat ditarik kesimpulan oleh peneliti dari uji peningkatan prestasi belajar di atas yaitu prestasi belajar pada kelas yang menggunakan multimedia interaktif ternyata lebih tinggi dibandingkan dengan hasil prestasi belajar pada kelas yang menggunakan mobile learning atau dengan kata lain penggunaan multimedia interaktif lebih efektif dalam meningkatkan prestasi belajar dibandingkan dengan mobile learning pada mata kuliah logika fuzzy di PVTE universitas sultan ageng tirtayasa.

Salah satu indikator efektif atau tidaknya penggunaan multimedia interaktif dan mobile learning dalam suatu proses pembelajaran adalah dengan melihat peningkatan prestasi belajar yang dicapai oleh mahasiswa. Prestasi belajar merupakan cerminan tingkat keberhasilan atau pencapaian tujuan dari proses belajar yang telah dilaksanakan dengan cara evaluasi oleh dosen yang bersangkutan. Prestasi belajar diartikan sebagai hasil akhir pengambilan keputusan tentang tinggi rendahnya nilai mahasiswa selama mengikuti proses belajar mengajar (PBM) pembelajaran dikatakan berhasil jika tingkat pengetahuan mahasiswa bertambah dari hasil sebelumnya.

Hasil uji-t menggunakan teknik one sample test antara skor pengetahuan awal (pre-test) dan skor penguasaan materi (post-test) pada kedua kelas eksperimen diperoleh informasi bahwa rata-rata penguasaan materi (post-test) meningkat jika dibandingkan rata-rata skor pre-test yaitu untuk kelas yang menggunakan multimedia interaksi rata-rata ternormalisasi sebesar 0.80 atau $80 \%$ serta pembelajaran menggunakan mobile learning rata-rata gain ternormalisasinya sebesar 0.570 atau $57 \%$.

Metode yang efektif dalam penelitian ini dapat meningkatkan prestasi belajar mahasiswa dapat dilihat dari rata-rata nilai gain ternormalisasi yang diperoleh dari kedua kelas eksperimen tersebut. Dari hasil perhitungan gain ternormalisasi untuk kelas eksperimen yang menggunakan multimedia interaktif diperoleh rata-rata gain ternormalisasi sebesar 0.80 atau $80 \%$ termasuk kategori tinggi sedangkan untuk kelas eksperimen yang menggunakan mobile learning rata-rata nilai gain ternormalisasinya sebesar 0.570 atau $57 \%$ termasuk kategori sedang. Hal ini membuktikan bahwa pemberian pembelajaran dengan menggunakan multimedia interaktif berbasis komputer lebih efektif dalam meningkatkan kemampuan prestasi belajar mahasiswa dibandingkan dengan pembelajaran dengan menggunakan mobile learning. Hal ini sesuai dengan pendapat Surya (2004) mengatakan bahwa belajar merupakan suatu proses usaha yang dilakukan oleh individu untuk memperoleh suatu perubahan tingkah laku yang baru secara keseluruhan sebagai hasil pengalaman individu itu sendiri dalam interaksinya dengan lingkungan.

Meningkatnya prestasi belajar mahasiswa pada kedua kelas eksperimen dipengaruhi oleh banyak faktor salah satunya yang mempengaruhi prestasi belajar adalah penggunaan media pembelajaran dalam hal ini penggunaan multimedia interaktif dan mobile learning. Keberadaan multimedia interaktif dapat mempengaruhi peningkatan kognitif mahasiswa. Hal ini disebabkan oleh adanya media pembelajaran seperti multimedia sangat mempengaruhi kinerja otak manusia sehingga mahasiswa terangsang dan menambah pemahaman mahasiswa tersebut. Hal ini senada yang diungkapkan oleh Darmawan (2012) yang menyatakan bahwa pembelajaran multimedia pada dasarnya merupakan pembelajaran yang diharapkan mampu memberdayakan semua aktivitas otak 
selama peserta didik atau mahasiswa melakukan aktivitas pembelajaran.

Peningkatan prestasi belajar mahasiswa pada kedua kelas eksperimen tersebut, diperkuat dengan hasil pengolahan data pada instrumen observasi. Dari hasil pengolahan data tersebut, penilaian dari observer menunjukkan bahwa penerapan penggunaan multimedia interaktif dan mobile learning dalam pembelajaran dapat meningkatkan keaktifan mahasiswa dalam belajar. Mahasiswa terlihat sangat antusias dan bersemangat dalam proses pembelajaran untuk mata kuliah logika fuzzy di PVTE universitas sultan ageng tirtayasa.

\section{PENUTUP}

\section{Kesimpulan}

Berdasarkan pada hasil penelitian, analisis data dan pembahasan yang telah dilakukan, maka peneliti dapat mengambil kesimpulan sebagai berikut: (1) penggunaan multimedia interaktif dapat meningkatkan prestasi belajar mahasiswa pada mata kuliah logika fuzzy di jurusan pendidikan vokasional teknik elektro Untirta dengan kategori tinggi. (2) penggunaan mobile learning dapat meningkatkan prestasi belajar mahasiswa pada mata kuliah logika fuzzy di jurusan pendidikan vokasional teknik elektro Untirta dengan kategori sedang. (3) terdapat perbedaan peningkatan prestasi belajar yang signifikan antara mahasiswa yang menggunakan multimedia interaktif dengan mahasiswa yang menggunakan mobile learning pada mata kuliah logika fuzzy di jurusan pendidikan vokasi teknik elektro Untirta. Jadi pembelajaran dengan multimedia interaktif lebih efektif dari pada dengan menggunakan mobile learning.

\section{DAFTAR PUSTAKA}

Ariani, N. (2010). Pembelajaran Multimedia di Sekolah. Jakarta: Prestasi Pustaka Karya.
Aunurrahman. (2011). Belajar dan Pembelajaran. Bandung: Alfabeta.

Darmawan, D. (2011). Teknologi Pembelajaran. Bandung: Alfabeta.

Darmawan, D. (2014). Inovasi Pendidikan, Pendekatan Praktik Teknologi Multimedia dan Pembelajaran On-line. Bandung: Remaja Rosda Karya.

Riduwan. (2010). Dasar-dasar Statistika. Bandung: Alfabeta.

Rusijono \& Mustaji. (2008). Penelitian Teknologi Pembelajaran. Jakarta: UNESA. University Press. Media.

Rusyan, A. T. (1999). Meningkatkan Mutu Kegiatan dalam Proses Belajar Mengajar di Sekolah Dasar, Cet. 2. Jakarta: PT. Kartanegara.

Rutoto, S. (2007). Pengantar Metedologi Penelitian. Kudus: FKIP. Universitas Muria Kudus.

Sanjaya, W. (2011). Perencanaan dan Desain Sistem Pembelajaran. Jakarta: Kencana Prenada Media.

Sugiyono. (2011). Metode Penelitian Pendidikan. Bandung: Alfabeta.

Suharjono \& Rufi'i. (2006). Metodologi Penelitian. Surabaya: Program Pascasarjana Universitas PGRI Adi Buana.

Sundayana, R. (2015). Statistika Penelitian Pendidikan. Bandung: Alfabeta.

Surya, M. (2004). Strategi Kognitif Dalam Proses Pembelajaran. Bandung: Alfabeta.

Surya, M. (2014). Psikologi Guru, Konsep dan Aplikasi. Bandung: Alfabeta.

Susilana, R \& Riyana. (2009). Media Pembelajaran. Bandung: $\mathrm{CV}$ Wacana Prima.

Wahyuddin. (2013). Statistika Terapan. Bandung: Mandiri. 